Advances in Geosciences, 5, 57-63, 2005

SRef-ID: $1680-7359 /$ adgeo/2005-5-57

European Geosciences Union

(c) 2005 Author(s). This work is licensed

under a Creative Commons License.

\title{
Airborne laser scanning and usefulness for hydrological models
}

\author{
M. Hollaus ${ }^{1}$, W. Wagner ${ }^{1}$, and K. Kraus ${ }^{2}$ \\ ${ }^{1}$ Christian Doppler Laboratory for "Spatial Data from Laser Scanning and Remote Sensing", Vienna Univ. of Technology, \\ Gusshausstr. 27-29, 1040 Vienna, Austria \\ ${ }^{2}$ Institute of Photogrammetry and Remote Sensing, Vienna Univ. of Technology, Gusshausstr. 27-29, 1040 Vienna, Austria
}

Received: 7 January 2005 - Revised: 1 August 2005 - Accepted: 1 September 2005 - Published: 16 December 2005

\begin{abstract}
Digital terrain models form the basis for distributed hydrologic models as well as for two-dimensional hydraulic river flood models. The technique used for generating high accuracy digital terrain models has shifted from stereoscopic aerial-photography to airborne laser scanning during the last years. Since the disastrous floods 2002 in Austria, large airborne laser-scanning flight campaigns have been carried out for several river basins. Additionally to the topographic information, laser scanner data offer also the possibility to estimate object heights (vegetation, buildings). Detailed land cover maps can be derived in conjunction with the complementary information provided by high-resolution colour-infrared orthophotos. As already shown in several studies, the potential of airborne laser scanning to provide data for hydrologic/hydraulic applications is high. These studies were mostly constraint to small test sites. To overcome this spatial limitation, the current paper summarises the experiences to process airborne laser scanner data for large mountainous regions, thereby demonstrating the applicability of this technique in real-world hydrological applications.
\end{abstract}

\section{Introduction}

Currently, modelling tools for simulating spatially distributed hydrological processes are in use that allow more detailed analysis in decision-making than lumped models. The quality of simulation and spatial process representation is crucially dependent on the input data that describe the variability of the natural conditions in an appropriate form. Therefore, a great demand for such information exists to minimise the uncertainties of the simulation results. A similar trend can be observed in the hydraulic modelling of floodplain flows. As reported in Marks and Bates (2000) twodimensional (2-D) hydraulic surface flow models are mostly constrained by inadequate parameterisation of topography

Correspondence to: M. Hollaus

(mh@ipf.tuwien.ac.at) and roughness coefficients, primarily due to insufficient or inaccurate data.

For all above-mentioned model types digital terrain models (DTMs) and their derived parameters such as slope, aspect, and drainage network form the basic model-input. Therefore, the accuracy of the DTM has a crucial influence on the model output. Advances in remote sensing techniques made it possible to generate high resolution DTMs for whole watersheds at reasonable costs. In the past, DTMs have been generated from stereoscopic analysis of aerial photographs or satellite imagery. In the last few years the technology of airborne laser scanning (ALS) has emerged, which allows to produce high-quality DTMs with accuracies less than $\pm 25 \mathrm{~cm}$, depending on the land cover, slope, flight parameters and environmental conditions. Several authors have summarised possible uses of products derived from ALS data for hydraulic applications. Charlton et al. (2003) have analysed the potential of ALS for mapping gravel-bed river environments for gathering high-resolution topographic data. Kraus (2003a) has studied the use of laser scanner DTMs for modelling flood risk areas. Pereira and Wicherson (1999) have summarised that laser scanning is a suitable technique to collect relief information for river management.

Airborne laser scanners also provide data for describing the landscape roughness of the earth's surface. As described by Schmugge et al. (2002) landscape roughness affects the transport of hydro-meteorological fluxes between the land surface and atmosphere as well as below the surface. Therefore, precise topographic information can be used to understand and calculate the effects of landscape roughness on evaporation, soil moisture, runoff, and soil erosion at field and landscape scale. Govers et al. (2000) have summarised that soil roughness does not only affect the runoff amount due to depression storage, but also affects the volume and rate of infiltration.

In the case of 2-D hydraulic flood models information describing the roughness of streams are needed. Cobby et al. (2001) have described an approach for estimating low vegetation heights using a logarithmic regression 
relationship that predicts the vegetation height from the standard deviations of detrended ALS heights in a small surrounding area. Mason et al. (2003) have reviewed approaches in literature how vegetation height data measured by ALS can be transformed to roughness coefficients. Finally, Cobby et al. (2003) have analysed the different frictional properties of floodplain vegetation features such as hedges and trees.

These studies have shown that the potential of ALS to estimate vegetation properties and roughness coefficients of streams is high, but still, several deficits in the physical interpretation and processing of ALS data remain. For example, Mason et al. (2003) have mentioned that the estimation of vegetation heights may cause problems, especially in areas of overlap between adjacent ALS swaths. Nevertheless, substantial progress has been made with georeferencing of ALS data, particularly with the minimisation of discrepancies between overlapping laser scanner strips. These discrepancies - in height as well as in planimetry - are unsatisfactory phenomena for end-users of the ground data. Therefore, Kager (2004) has developed an adjustment strategy for correcting the exterior orientation elements as recorded by differential-GPS (dGPS) and Inertial Measurement Unit (IMU), as well as interior orientation elements concerning the Scanner-dGPS-IMU system. The method applies correction polynomials in the time domain to all degrees of freedom as determined by the dGPS-IMU components and to the relative orientation parameters between those scanner-system components. All these parameters are determined simultaneously with hybrid block adjustment by least squares. The result of this pre-processing step is a high quality georeferenced 3-D point cloud, which has to be filtered into terrain and non-terrain points. A good overview of existing filtering strategies is given in Sithole and Vosselman (2003). In this study we use a hierarchic robust filtering technique described in Kraus and Pfeifer (1998) and Briese et al. (2002). In order to improve the quality of ALS derived DTMs, Briese (2004) has investigated an algorithm for modelling threedimensional breaklines from ALS data.

Therefore, the algorithms for processing large ALS data are available and provide together with colour-infrared (CIR) orthophotos a valuable data source for the parameterisation of hydraulic/hydrologic models. The complementary information content of ALS data and CIR orthophotos, as described in Sect. 2, is well suited for object-oriented land cover classifications (Sect. 3). In Sect. 4 we discuss experiences, limitations, and future research needs with respect to use ALS data over large regions. Furthermore, we show the potential of ALS data and CIR orthophotos for providing hydrologic/hydraulic relevant input data and show an exemplary result of an object-oriented land cover classification including different roughness classes, followed by the conclusion in Sect. 6. It is our hope that this paper raises the interest of hydrologists to use the full information content of this emerging remote sensing technique.

\section{Information content of laser scanner data and or- thophotos}

Airborne laser scanning and photogrammetry are remote sensing methods that are in use for several environmental applications. The following short overview of the two techniques is based on Baltsavias (1999), Kraus (2003b), and Maas and Vosselman (2004). Additionally, the different information content for deriving hydrologic/hydraulic relevant land cover information is outlined in detail below.

Airborne laser scanning, often referred to as LIDAR or laser altimetry, is an active remote sensing technique, which was originally designed to measure the topography of the Earth's surface. A laser emits short infrared pulses towards the Earth's surface and a photodiode measures the backscattered echoes. The count of echoes is depending on the objects within the travel path of the laser pulse. Therefore, state-of-the-art laser scanner systems measure the round-trip time of multiple echoes from one laser pulse, e.g. firstand last-pulse, or up to five pulses. Laser scanner systems recording the full waveform of the backscattered signal have become commercially available recently (Wagner et al., 2004a). Some laser scanner systems measure not only the range but also the intensity information. Unfortunately, an unfavourable signal-to-noise ratio and insufficient calibration restricted the use of the intensity data in the past.

Airborne laser scanning systems are characterised by pointwise sampling mechanisms, whereas photogrammetry delivers full area coverages. As a passive system, photogrammetry is strongly depending on weather conditions. The fundamental advantages of photogrammetry are the spectral/textural information content of the images, the large area coverages, the high spatial resolution, the very high position accuracy, and the possibility of direct identifications and measurements of objects. Furthermore, the gathered imagery can be used for generation of orthoimages, DTMs, and digital surface models (DSMs). On of the disadvantages is the poor visibility into forested areas. Additional drawbacks are the fact that for stereoscopic analysis (DTM and DSM generation) the point on the surface must be visible from two different locations, and the very time-consuming interpretation work.

In contrast to photogrammetric systems, ALS ones are characterised by a simple measurement geometry meaning that the 3-D-position of a point on the surface is measured from one location. This allows the generation of precise DTMs also for urban areas with narrow alleys and wooded areas, where the penetration rate through the tree canopy mainly depends on the density of trees and the season. However, the high point density achievable with ALS systems permits the generation of high accuracy DTMs and DSMs. In forested areas the difference between the DSM and the DTM represents the vegetation height (Fig. 1, left), which enables the derivation of other important parameters like biomass. Furthermore, the mapping of surfaces with very little/no texture is possible with ALS. Finally, a high degree of automatisation for analysing the ALS data can be achieved. 

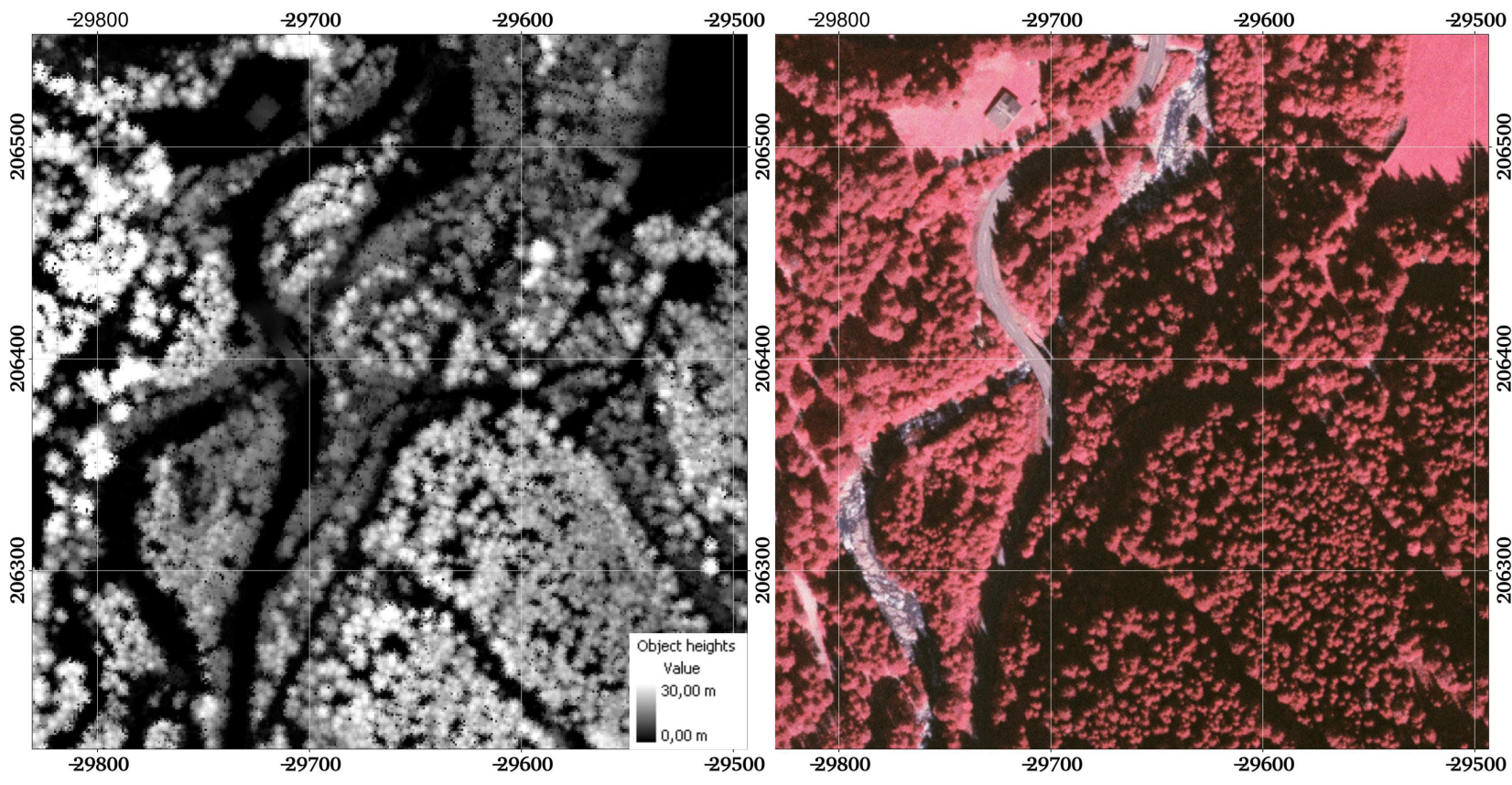

Fig. 1. Comparison of ALS data and CIR orthophotos; (left) the object heights are calculated from ALS data, spatial resolution $1.0 \mathrm{~m}$; (right) CIR orthophoto with a spatial resolution of $0.25 \mathrm{~m}$; coordinates are in Gauß-Krüger (reference meridian M28).

As the primarily result of laser scanning is a 3-D-point cloud, additionally information for the classification and identification of objects is necessary. Therefore, several authors (Ackermann, 1999; Baltsavias, 1999; Kraus, 2003b) have proposed the use of the synergetic information content of photogrammetrically derived imagery and ALS data. Especially the height information of ALS data (Fig. 1) leads to enormous improvements of land cover classifications in shaded areas. Furthermore, this information can be used for the determination of roughness coefficients.

In order to obtain the largest benefit of combined analysis, the data should be gathered simultaneously or within short time intervals. Due to cost and the fact that many datasets are already available from several projects, the data processing algorithms have to consider the different qualities and properties of the available data.

\section{Object-oriented land cover classification}

Deriving land cover information from remotely sensed data is one of the most important tasks in earth observation. Since the first Landsat satellite, launched in 1972, remote sensing has made enormous progress in terms of data availability, and improved spatial and temporal resolution. In the field of ALS substantial progresses has been made during the last decade. Cobby et al. (2003) have reported the usefulness of ALS data for 2-D river flood models providing spatially distributed floodplain topography for model bathymetry and vegetation heights for the determination of roughness coefficients. Normally the roughness is described by Manning's roughness coefficients that can be expressed as a function of land cover (Van der Sande et al., 2003; De Roo et al., 2001). Unfortunately, detailed, actual, and hydraulic relevant land cover information is normally not available. Since DTMs are generated from ALS data more frequently, there is now the possibility to use this data source together with orthophotos for land cover classifications. However, for exploring the full information content of these data traditionally pixel-based classification algorithms are not suitable. Therefore, object-oriented approaches have been proposed from several authors during the last years (Blaschke and Strobl, 2001; Darwish et al., 2003; Benz et al., 2004). The practical realisation of the object-oriented approach postulates the existence of objects. In this context an object is characterised by an amount of spatial connected pixels that represents a meaningful, homogeneous landscape patch. The process for building these objects is normally called segmentation and was the research area of many groups in the past. Unfortunately, most of the algorithms were developed for research experiments only. The commercial available software package eCognition (eCognition, 2005) has realised a multiresolution segmentation approach together with an objectbased fuzzy logic classification algorithm. Detailed descriptions of the multi-resolution segmentation approach can be found in Baatz and Schäpe (2000).

In the current study an object-based land cover classification is performed using the software eCognition, whereas the selection of the land cover classes was driven by hydraulic relevant roughness coefficients. As data sources ALS data and CIR orthophotos are available, which are described in detail in the following Section. 


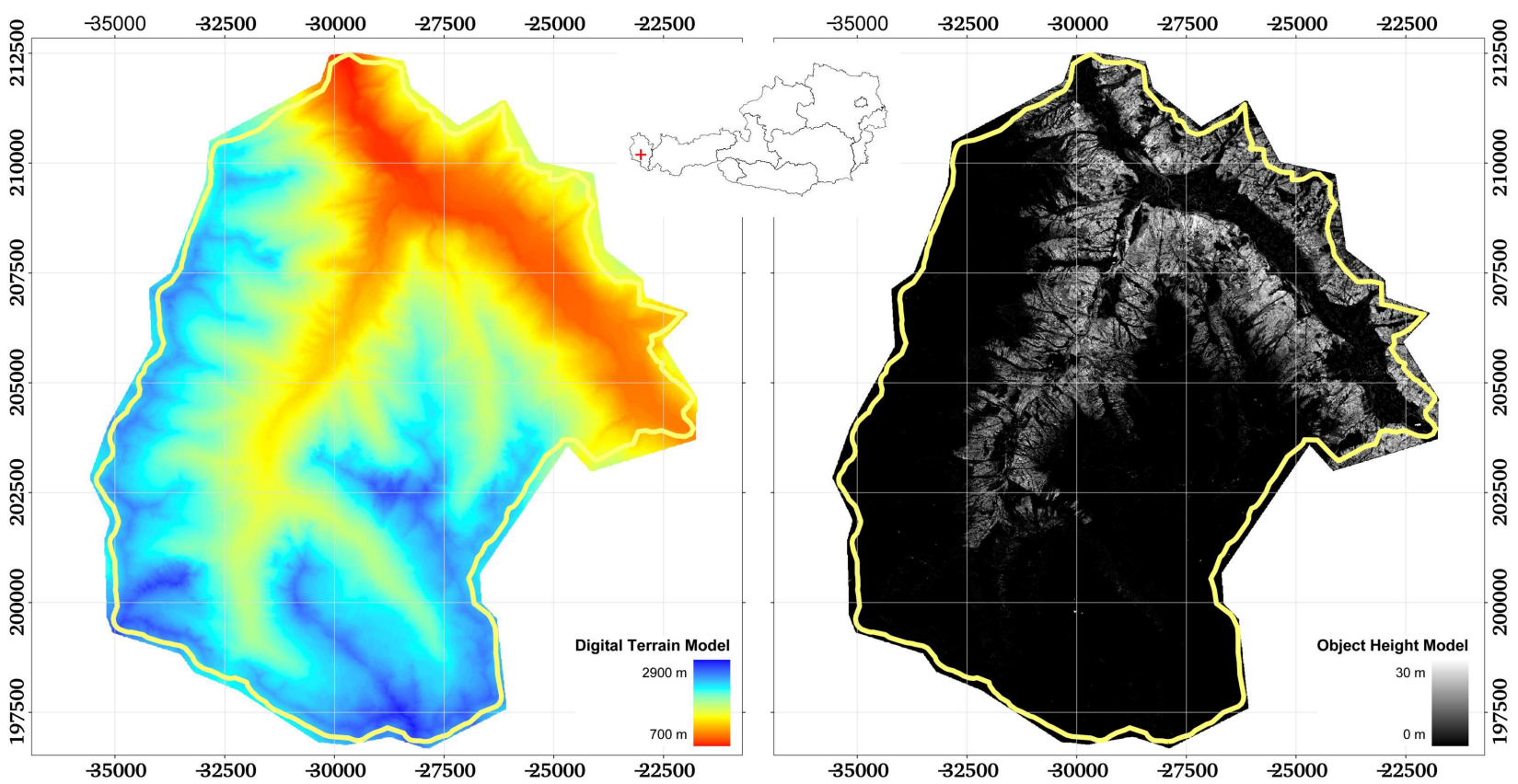

Fig. 2. Location of the study area; (left) digital terrain model calculated from 76 laser scanner strips; (right) object height model derived from ALS data, the greyscale corresponds to the object heights; spatial resolution of the data $1 \mathrm{~m}$, coordinates are in Gauß-Krüger (reference meridian M28).

\section{Experiences from a larger-scale catchment}

The applicability of novel earth observation technologies is put to a test by applying them over large-scale catchments. To demonstrate what is already feasible now in an operational fashion for hydrologic applications we discuss the results for a $128 \mathrm{~km}^{2}$ large catchment in difficult topographic condition. This is not only done to highlight what can be done now, but also show required technological improvements and research needs.

So far, studies on the potential of ALS for providing input data for hydrologic/hydraulic applications has been confirmed to small test sides. Kondoh and Higuchi (2001), Wealands et al. (2004), Schmugge et al. (2002), De Roo et al. (2001), and others have outlined the usefulness of remotely sensed data for distributed hydrological models. Those studies suggest ALS data in combination with high spatial resolution multi-spectral imagery for estimating aerodynamic landscape roughness, vegetation cover, and leaf area indices. Furthermore, ALS could be used for the determination of roughness coefficients for river flood models in two ways: The roughness coefficients can either be derived from the vegetation heights, type, and density as reported by Cobby et al. (2003), and Mason et al. (2003) or be connected to hydraulic relevant land cover classes (Brügelmann and Bollweg, 2004). However, it is not clear how close these suggested applications are to becoming operational.

As a real world example we analyse ALS data from a test region in Vorarlberg/Austria, which were acquired in the framework of a commercial mapping project. The study region, located in the southern part of the federal state of Vorarlberg, covers the "Montafon" district as shown in Fig. 2. Several small mountain streams run through the study area whereas the two main streams are the Suggadinbach (south to north) and the Ill (south-east to north-west). The complex mountainous landscape of the study area shows many different facets and is characterised by hilly to alpine terrain, with altitudes rising from $800 \mathrm{~m}$ to $2900 \mathrm{~m}$. The land cover is characterised by coniferous and mixed forests, shrubs, meadows, and sparsely settled areas in the valley floors.

The ALS data were gathered by two flight-campaigns performed by the company TopScan, Germany. The first flight, consisting of 24 laser scanner strips covering the valley, took place on 10 December 2002. The second flight was performed on 19 July 2003, and consists of 52 laser scanner strips covering the mountainous regions of the study area. During the winter flight the pulse repetition rate was $25 \mathrm{kHz}$, for the summer flight it was $50 \mathrm{kHz}$. Consequently, the average point density on ground was higher for the summer campaign (2.7 points per $\left.\mathrm{m}^{2}\right)$ than for the winter campaign (0.9 points per $\mathrm{m}^{2}$ ). The total amount of laser scanner points for the two flight-campaigns is 650 millions including first- and last-pulses.

The laser-scanning DTM (Fig. 2) and DSM have been generated using the simultaneously hybrid block adjustment for the georeferencing of the laser scanner strips (Kager, 2004) and the hierarchic robust filtering technique for classifying the ALS points into terrain and non-terrain points. The used 


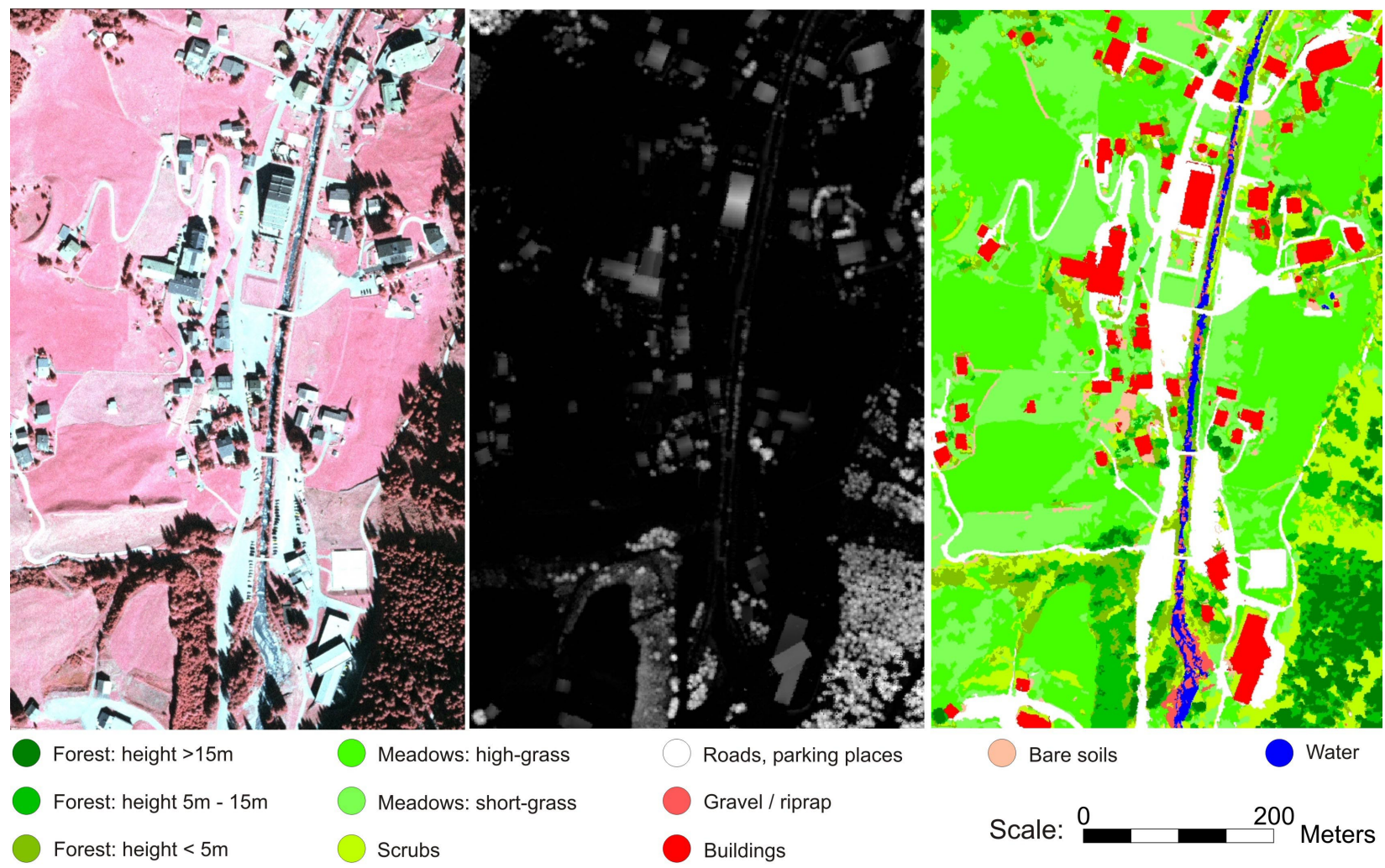

Fig. 3. Land cover map with hydrologic/hydraulic relevant classes; shown is a subset of the study area; (left) CIR orthophotos; (middle) object height model derived from ALS data; (right) land cover map with a spatial resolution of 0.25 m, derived from ALS data and CIR orthophotos.

algorithms are implemented into the commercial softwarepackage Scop++ (Scop++ 2005). Detailed information for deriving DSMs and DTMs can be found in Pfeifer (2003) and Briese et al. (2002).

Additionally CIR digital orthophotos with a ground resolution of $0.25 \mathrm{~m}$ were available. Both orthophotos and ALS data were provided by the provincial government Vorarlberg.

The relatively high penetration rate of ALS into forests particularly during the winter season enables the derivation of precise DTMs also in wooded areas (Kraus and Pfeifer, 1998). Relatively large errors in the order of several meters may occur in rare instances, when dense evergreen forest covers large patches of steep inclinations. Furthermore, the DTM shows inaccuracies near surface breaklines, which leads to incorrect object heights. In order to improve the quality of ALS derived DTMs, Briese (2004) has investigated an algorithm for modelling three-dimensional breaklines from ALS data that will be used for future DTM generations. Apart from these situations the object height model can be calculated by subtracting the DTM from the DSM, and represents the vegetation (forest) heights (Fig. 2, right).

The spatial resolution of the calculated DTM is $1 \mathrm{~m}$. The quality of the DTM is depending on the ALS point density, the slope, and the land cover and is in the range of few centimetres for high point densities and low slopes and increase to few decimetres for steep slopes with low point density. More detailed information about ALS-DTM qualities can be found in Kraus et al. (2004). Additionally to the object height model, the forest ground cover, calculated from the object height model, and the normalised difference vegetation index (NDVI), calculated from the CIR orthophotos, are used for the land cover classification, as shown in Fig. 3 (right). The classification has been carried out with the software eCognitioin (eCognition, 2005), where the knowledge-based classification rules are mainly driven by the complementary information content of the two data sources described in Sect. 2. For the current study area the land cover classes buildings, sealed surfaces (roads, parking places), bare soils, gravel/riprap, pastures/meadows (short-, high-grass), scrubs (sparse, dense), forests (sparse, dense), and young forests (sparse, dense) are used. The differentiation of the land cover classes meadows with high-grass and dense scrubs is not possible in areas, which are covered by shadows in the CIR orthophotos, due to the missing spectral information and the inaccuracies in the object height model. Nevertheless, the quality of the land cover classification is high, as can be seen in Fig. 3 (right). Unfortunately, the spectral information of the black areas in the CIR orthophoto (Fig. 3, left), representing shaded areas (e.g. around buildings), cannot be used for the land cover classification. With the help of ALS heights 
(Fig. 3, middle), high thematic accuracies can be reached also for these areas. With minor manual post-processing of the land cover map, which is the common practice in commercial projects, a kappa coefficient higher than 0.95 can be reached, which is a reasonable good result. Even considering the cost implications, this high thematic accuracy is only achievable with these datasets.

The derived land cover classes shown in Fig. 3 (right) can be used for the determination of roughness coefficients of hydraulic river flood models. The empirical roughness coefficients for each land cover class can be found in the literature. A more physically based approach is the calculation of the roughness coefficient from the ALS data directly, which requires the correct measurement of vegetation heights also for short vegetation types such as grasses or scrubs. As the laser pulse duration of current ALS systems is in the order of $10 \mathrm{~ns}$ it is only possible to distinguish vegetation classes, which are taller than $1.5 \mathrm{~m}$ (Wagner et al., 2003). Furthermore, it is not always clear which vegetation height is represented by the measured laser pulse due to different penetration depths (Wagner et al., 2004b). These facts make it impossible to measure short vegetation heights directly with current systems. The rapid development of ALS technology is expected to improve the situation in near future.

\section{Conclusions}

Since the disastrous floods in Austria in the year 2002, large ALS campaigns have been carried out along several river courses (e.g. the rivers "Kamp", "Drau", "Alm", and parts of the "Danube"). Furthermore, the Austrian federal state of Vorarlberg is mapping and Tirol is planing to map the whole areas of their provinces with ALS within the next years. Several other federal states of Austria have similar intentions. Therefore, ALS data will become available for many complete catchment areas in the near future. The same trend can be observed in many other countries. Additionally, countrywide orthophotos are often available and will be updated in an interval of 5-10 years. This high spatial resolution data source is in use for updating topographic maps, for agricultural purposes, and for several other environmental applications. Until now ALS flight campaigns are expensive. In consideration of the fact that the level of automation for the data processing is very high and that the data can be used for multiple purposes ALS data provide an attractive information source. For small study areas, the potential of ALS data to derive hydrologic/hydraulic relevant information has already been shown in several studies. In this paper we have discussed the experiences of processing ALS data, which were acquired in the framework of a commercial mapping project, for a large mountainous region. We could show that the simultaneously hybrid block adjustment for georeferencing of the laser scanner strips and the hierarchic robust filtering technique are adequate methods to derive DTMs, DSMs, and digital object height models. However, some inaccuracies of the vegetation height model arose in areas covered by homogeneous meadows with high-grass or scrubs due to the technical limitations of the current laser scanner systems. New ALS systems, which provide calibrated intensities of the laser echoes or which record the full echo-waveform, may provide crucial information to overcome these problems (Wagner et al., 2004b) and a more physically approach for deriving e.g., roughness coefficients can be applied.

Finally, this study has shown that the complementary information content of ALS data and CIR orthophotos is an excellent data source for object-oriented land cover classifications needed for hydrologic/hydraulic applications. These data can be used to support the preparation of the necessary information needed for integrated river basins to comply with the EU Water Framework Directive. The high quality of topographic and thematic input information for hydrologic/hydraulic models leads to a reduction of uncertainties of the model outputs.

Acknowledgements. We would like to thank the Landesvermessungsamt Feldkirch for granting the use of the ALS data and the CIR orthophotos for the purpose of this study. Furthermore, we would like to thank C. Eberhöfer and H. Kager from the Institute of Photogrammetry and Remote Sensing, Vienna University of Technology, for the processing of the laser scanner data.

Edited by: P. Krause, K. Bongartz, and W.-A. Flügel

Reviewed by: anonymous referees

\section{References}

Ackermann, F.: Airborne laser scanning - present status and future expectations, ISPRS Journal of Photogrammetry and Remote Sensing, 54, 64-67, 1999.

Baatz, M. and Schäpe, A.: Multiresolution Segmentation: An optimization approach for high quality multi-scale image segmentation. Angewandte Geographische Informationsverarbeitung XII, Beiträge zum AGIT-Symposium Salzburg 2000, Salzburg, Karlsruhe, Herbert Wichmann Verlag, 2000.

Baltsavias, E. P.: A comparison between photogrammetry and laser scanning, ISPRS Journal of Photogrammetry and Remote Sensing, 54, 83-94, 1999.

Benz, U. C., Hofmann, P., Willhauck, G., Lingenfelder, I., and Heynen, M.: Multi-resolution, object-oriented fuzzy analysis of remote sensing data for GIS-ready information, ISPRS Journal of Photogrammetry and Remote Sensing, 58, 239-258, 2004.

Blaschke, T. and Strobl, J.: What's wrong with pixels? Some recent developments interfacing remote sensing and GIS, GIS Zeitschrift für Geoinformationssysteme, 6, 12-17, 2001.

Briese, C., Pfeifer, N., and Dorninger, P.: Applications of the Robust Interpolation for DTM determination, in: International Archives of Photogrammetry and Remote Sensing, Photogrammetric Computer Vision (PCV'02), 9-13 September 2002, Graz, Austria, urlhttp://www.isprs.org/publications/archives.html, 2002.

Briese, C.: Three-dimensional Modelling of Breaklines from Airborne Laser Scanner Data, presentation in: International Archives of Photogrammetry and Remote Sensing, XXth ISPRS Congress, Istanbul, Turkey, 12-23 July 2004, CD-ROM, 2004.

Brügelmann, R. and Bollweg, A. E.: Laser Altimetry for River Management, in: International Archives of Photogrammetry and 
Remote Sensing, XXth ISPRS Congress, Istanbul, Turkey, 12-23 July 2004, CD-ROM, 2004.

Charlton, M. E., Large, A. R. G., and Fuller, I. C.: Application of airborne LIDAR in river environments: the river COQUET, Northumberland, UK, Earth Surf. Process. Landforms, 28, 299306, 2003.

Cobby, D. M., Mason, D. C., and Davenport, I. J.: Image processing of airborne scanning laser altimetry data for improved river flood modelling, ISPRS Journal of Photogrammetry and Remote Sensing, 67, 121-138, 2001.

Cobby, D. M., Mason, D. C., Horritt, M. S., and Bates, P. D.: Twodimensional hydraulic flood modelling using a finite-element mesh decomposed according to vegetation and topographic features derived from airborne scanning laser altimetry, Hydrol. Process., 17, 1979-2000, 2003.

Darwish, A., Leukert, K., and Reinhardt, W.: Urban Land-Cover Classification: An Object Based Perspective, in: Proceedings 2nd GRSS/ISPRS Joint Workshop on Data Fusion and Remote sensing over Urban Areas, Berlin, Germany, 22-23 May 2003, CD-Rom, 278-282, 2003.

De Roo, A., Idijk, M., Schmuck, G., Koster, E., and Lucieer, A.: Assessing the Effects of Land Use Changes on Floods in the Meuse and Oder Catchment, Phys. Chem. Earth (B), 26, 7-8, 593-599, 2001.

eCognition: January: http://www.definiens-imaging.com/, 2005.

Govers, G., Takken, I., and Helming, K.: Soil roughness and overland flow, Agronomie, 20, 131-146, 2000.

Kager, H.: Discrepancies between overlapping laser scanner strips - simultaneous fitting of aerial laser scanner strips, in: International Archives of Photogrammetry and Remote Sensing, XXth ISPRS Congress, Istanbul, Turkey, 12-23 July 2004, CD-ROM, 2004.

Kondoh, A. and Higuchi, A.: Relationship between satellite-derived spectral brightness and evapotranspiration from a grassland, Hydrol. Process., 15, 1761-1770, 2001.

Kraus, K. and Pfeifer, N.: Determination of terrain models in wooded areas with airborne laser scanner data, ISPRS, Journal of Photogrammetry and Remote Sensing, 53, 193-203, 1998.

Kraus, K.: LaserScanDTMs for Modeling Flood Risk Areas, GIS (Geo-Informations-Systeme) (invited), 12, 26-31, 2003a.

Kraus, K.: Laser-Scanning - ein Paradigmawechsel in der Photogrammetrie, Bulletin SEV/VSE (invited), 9, 19-22, 2003b.

Kraus, K., Briese, C., Attwenger, M., and Pfeifer, N.: Quality Measures for Digital Terrain Models, in: International Archives of Photogrammetry and Remote Sensing, XXth ISPRS Congress, Istanbul, Turkey, 12-23 July 2004, CD-ROM, 2004.

Maas, H. G. and Vosselman, G.: Flugzeug-Laserscanning. Photogrammetrie, Fernerkundung, Geoinformation (PFG), Heft 4, 257-258, 2004.
Marks, K. and Bates, P.: Integration of high-resolution topographic data with floodplain flow models, Hydrol. Process., 14, 21092122, 2000.

Mason, D. C., Cobby, D. M., Horritt, M. S., and Bates, P. D.: Floodplain friction parameterisation in two-dimensional river flood models using vegetation heights derived from airborne scanning laser altimetry, Hydrol. Process., 17, 1711-1732, 2003.

Pereira, L. M. G. and Wicherson, R. J.: Suitability of laser data for deriving geographical information: A case study in the context of management of fluvial zones, ISPRS Journal of Photogrammetry and Remote Sensing, 54, 105-114, 1999.

Pfeifer, N.: Oberflächenmodelle aus Laserdaten, Österreichische Zeitschrift für Vermessung and Geoinformation, 4, 243-252, 2003.

Schmugge, T. J., Kustas, W. P., Ritchie, J. C., Jackson, T. J., and Rango, A.: Remote sensing in hydrology, Advances in Water Resources, 25, 1367-1385, 2002.

Scop++: : http://www.ipf.tuwien.ac.at/products, January, 2005.

Scop++: http://www.inpho.de, January, 2005.

Sithole, G. and Vosselman, G.: ISPRS Comparison of Filters, Proceedings of the ISPRS working group III/3 workshop, 3-D reconstruction from airborne laserscanner and InSAR data, Dresden, Germany, 8-10 October 2003, edited by: Maas, H.-G., Vosselman, G., and Streilein, A., Volume XXXIV, PART 3/W13; CDRom, 8 pages, 2003.

Van der Sande, C. J., De Jong, S. M., and De Roo, A. P. J.: A segmentation and classification approach of IKONOS-2 imagery for land cover mapping to assist flood risk and flood damage assessment, International Journal of Applied Earth Observation and Geoinformation, 4, 217-229, 2003.

Wagner, W., Ullrich, A., Briese, C.: Der Laserstrahl und seine Interaktion mit der Erdoberfläche, Österreichische Zeitschrift für Vermessung and Geoinformation, VGI 4/2003, 223-235, 2003.

Wagner, W., Ullrich, A., Melzer, T., Briese, C., and Kraus, K.: From single-pulse to full-waveform airborne laser scanners: Potential and practical challenges, in: International Archives of Photogrammetry and Remote Sensing, XXth ISPRS Congress, Istanbul, Turkey, 12-23 July 2004, CD-ROM, 2004a.

Wagner, W., Eberhöfer, C., Hollaus, M., and Summer, G.: Robust Filtering of Airborne Laser-Scanner Data for Vegetation Analysis, Proceedings of the ISPRS working group VIII/2: LaserScanners for Forest and Landscape Assessment, Freiburg, Germany; 3-6 October 2004, International Archives of Photogrammetry, Remote Sensing and Spatial Information Sciences, Volume XXXVI, Part 8/W2, 2004b.

Wealands, S. R., Grayson, R. B., and Walker, J. P.: Quantitative comparison of spatial fields for hydrological model assessment some promising approaches, Advances in Water Resources, 28, 15-32, 2004. 